\title{
Performances and Skills of Cotabato City's Mathematics Pre-service Teachers in Problem Solving
}

\author{
Mobarac R. Dimasindel \\ Cotabato City State Polytechnic College \\ movz_20@yahoo.com
}

\begin{abstract}
The performances in problem solving of mathematics pre-service teachers in Cotabato City was determined in this study using qualitative research design. The Polya's theory (1954) on problem solving skills in terms of understanding the problem, devising a plan, carrying out the plan, and looking back was used in classifying and describing the performances of the respondents in the conducted problem solving skill test. Ten (10) mathematics preservice teachers from Cotabato City State Polytechnic College enrolled for the school year 2014-2015 were chosen as respondents using purposive sampling. The study then found out that the respondents' level of proficiency in problem solving in terms of understanding the problem, devising a plan, and looking back is 'Developing' as they cannot define the problems adequately and cannot follow them to conclusion. However, they are at the level of 'Approaching Proficiency' in terms of carrying out the plan.
\end{abstract}

Keywords: problem solving skills, understanding the problem, devising a plan, carrying out the plan, looking back

\section{Introduction}

The deteriorating quality of mathematics instruction is one of the issues in some countries including the Philippines. In fact, the poor performances of Filipino students in some disciplines including mathematics have been observed for many years in the annually conducted National Achievement Test. As observed, one factor that can be associated to this is the teachers' utilization of algorithmic approach in their instruction where students are not trained to be critically-minded as they are guaranteed with solutions of problems of a certain type.

Yuan (2013) pointed out that a student solving an equation has not really learned the mathematics language if he has not understood it. This points out that students need to be totally oriented with the ways they come up with solutions as well as with the details of how they take such ways. Mathematics problem solving according to Jakel and Schreiber (2013, as cited by Laurillard) involves self-examination because individuals engaged in it tend to contemplate dealing with difficult problems that cannot be solved by using the standard methods in which they evaluate the ways they solve the problems including the strategies that they utilize and their representations of the problems.

In the Philippines many students seemed not performing well in problem solving because of the poor ratings that they get in the National Achievement Test. Culaste (2011) stated in her study that the students were below average in the nine cognitive skills. Furthermore, they had low metacognitive prediction and evaluation dimensions on their 
cognitive skills which implied that their metacognitive dimensions were still untapped and not developed.

In 2003 the Philippines ranked third from the bottom among 25 countries in the fourth grade and fifth from the bottom among 45 countries in the eighth grade (Philippine Daily Inquirer, 2010 as cited in Culaste, 2011). Ogena, Lana, and Sasota (2010) reported during the $11^{\text {th }}$ National Convention on Statistics that the Philippines ranked tenth among 10 countries that participated in the study on Trends in International Mathematics and Science Study (TIMSS) with an average scale score 355 only. Furthermore, Sangcap (2010) mentioned that the TIMSS which was conducted in 2003 showed that Filipino students' poor mathematical performances have placed the country in the $36^{\text {th }}$ rank out of 38 nations worldwide. These are maybe some of the reasons why an ever-changing revision and development of mathematics curriculum occur in the country's educational system.

With regard to the current changes in the curriculum, numerous publications have highlighted the need for further development of students' thinking skills and thinking about their thinking (Kerry \& Wilding, 2004, as cited in Ader, 2014). As to the most notable men who committed themselves in studying problem solving, English, Lesh, and Fennewald (2008) claimed that Polya was one among the individuals who have contributed much in the development of the study on problem solving as he had seminar engagements on solving problems, and for he is believed to have influenced mathematics scholars due to his four steps in problem solving which include understanding the problem, devising a plan, carrying out the plan, and looking back.

The persistency to address the issue on poor performances in mathematics among students in the locality as indicated in their scores in the battery test, entrance examination, and Licensure Examination for Teachers has led the researcher to determine the performances of mathematics pre-service teachers in Cotabato City. This is to further provide a reference among mathematics faculties to innovate their instruction. A number of educators believe that it is a significant step to develop students' metacognitive knowledge and skills. They also emphasized its necessity especially in connection with mathematical problem solving (Gill, 2004, as cited in Ader, 2014) and mathematical sense making (Henningsen \& Stein, 1997, as cited in Ader, 2014).

\section{Research Design}

This study utilized a qualitative research design for it determined and described the problem solving skills of BS Education Mathematics Students of Cotabato City State Polytechnic College for school year 2014-2015 and the ways such skills were demonstrated by them in solving mathematical problems. It involved 10 respondents only due to the small number of students taking mathematics as their field of specialization in the city. Merriam 
(2009, p. 14) states that "the overall purposes of qualitative research are to achieve an understanding of how people make sense out of their lives, delineate the process of meaningmaking, and describe how people interpret what they experience”.

A five-item researcher-made problem solving skill test validated was used to determine the problem solving skills of BS Education Mathematics Students. The test contained problem solving items covering algebra, calculus, and number theory. There were five items which were categorized into 'easy' (1 and 2), 'moderately difficult' (3 and 4), and 'difficult' (5) involved in the said problem solving skill test. The respondents' performances and responses in a test were checked by three experts using analytic rubrics with ratings elaborated by them in the interview. The problem solving skills of BS Education Mathematics Students were further discussed comprehensively through the use of focus group discussion based on how they constructed their solutions in terms of understanding the problem, devising a plan, carrying out the plan, and looking back.

\section{Results}

\section{Mathematics Pre-service Teachers' Performances in Problem Solving}

Table 1 shows the levels of proficiency of the respondents on Problem 1. Problem 1 required them to determine a number if eight times the number plus twice the number is two hundred twenty. The table shows that respondents A, B, C, D, H, and J are rated 'Developing' for they were not able to provide all of the required given values and variables to be extracted from the statement although they utilized letters of their own choice to represent the number. Only respondents $\mathrm{B}, \mathrm{D}$, and $\mathrm{H}$ were able to state the letter of their choice as the variable representing the number.

Table 1.

Respondents' Level of Proficiency in Problem 1

\begin{tabular}{|c|c|c|c|c|}
\hline Respondent & $\begin{array}{l}\text { Understanding the } \\
\text { Problem }\end{array}$ & Devising a Plan & $\begin{array}{l}\text { Carrying out the } \\
\text { Plan }\end{array}$ & Looking Back \\
\hline A & $\mathrm{D}$ & $\mathrm{P}$ & $\mathrm{P}$ & $\mathrm{P}$ \\
\hline B & $\mathrm{D}$ & $\mathrm{P}$ & $\mathrm{P}$ & $\mathrm{P}$ \\
\hline $\mathrm{C}$ & $\mathrm{D}$ & $\mathrm{P}$ & $\mathrm{P}$ & $\mathrm{P}$ \\
\hline D & $\mathrm{D}$ & $\mathrm{P}$ & $\mathrm{P}$ & $\mathrm{P}$ \\
\hline $\mathrm{E}$ & B & $\mathrm{D}$ & $\mathrm{P}$ & $\mathrm{P}$ \\
\hline $\mathrm{F}$ & B & $\mathrm{P}$ & $\mathrm{P}$ & $\mathrm{P}$ \\
\hline G & B & $\mathrm{P}$ & $\mathrm{P}$ & $\mathrm{P}$ \\
\hline $\mathrm{H}$ & $\mathrm{D}$ & $\mathrm{D}$ & $\mathrm{D}$ & $\mathrm{D}$ \\
\hline I & B & $\mathrm{B}$ & B & $\mathrm{B}$ \\
\hline $\mathrm{J}$ & $\mathrm{D}$ & $\mathrm{P}$ & $\mathrm{P}$ & $\mathrm{P}$ \\
\hline
\end{tabular}

Respondents E, F, G, and I were rated 'Beginning' in terms of understanding the problem for they were not able to provide variables and other details of the statement. They did not include a letter to stand as a variable. Data generated from focus group discussions revealed 
that the respondents were not able to extract key information from the statement except for the number being looked for. They said that they prefer going directly to the equation that they can formulate based on how they comprehend the statement. Respondents E, F, and G claimed that going directly to the manipulation of the equation was what they prioritized for they want to have the answer immediately rather than enumerating the variables and values that could be extracted from the problem.

The majority of the respondents, A, B, C, D, F, G, and J, in terms of devising a plan were rated 'Proficient' because they were able to formulate an equation correctly although they utilized different letters as their variables in their respective equation. Respondent $\mathrm{H}$ was not able to come up with a correct equation as he used two different letters representing the same number. His equation was $8 x+2 m=220$ where $x$ and $m$ are variables representing the number being looked for. Respondent I formulated an equation $8 x n+2=0$ which is obviously a wrong understanding of the problem. He extracted and translated values and mathematical operations from the statement without considering the number to be represented by a letter to stand as the literal coefficient of eight and two.

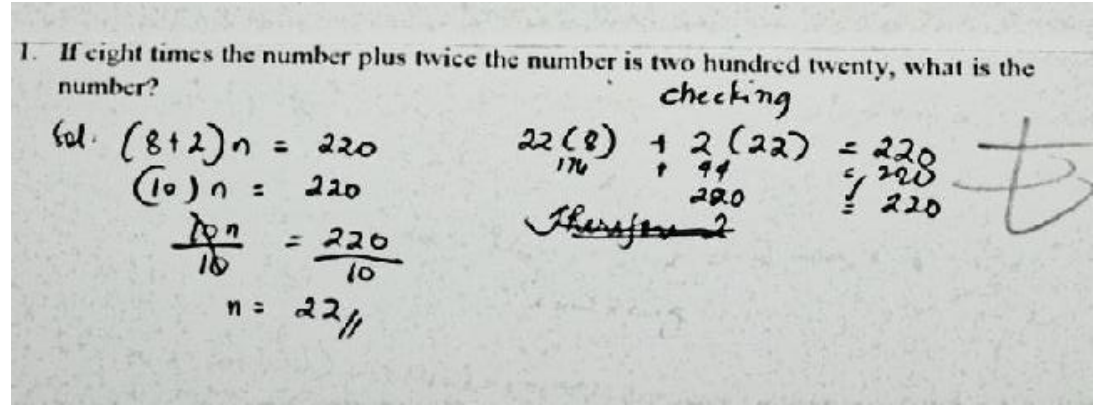

Figure 1. Sample of respondent's answers on Problem 1

Figure 1 shows that most of the mathematics pre-service teachers were 'Proficient' except respondents $\mathrm{H}$ and $\mathrm{I}$ in terms of carrying out their plan as implied by their algebraic manipulation of numbers, variables, and operations in the equation that they formulated. Respondents A, B, C, D E, F, G, and J were able to come up with 22 as the answer. Respondent $\mathrm{H}$ was rated 'Developing' for he added $8 x$ and $2 m$ to give $10 m=220$. Respondent I was also rated 'Developing' for he substituted 220 into $n$ and directly multiplied it by 8 before he added 2 into the product of the said numbers and ended with 1,762 as the answer. He had followed the PEMDAS rule in his manipulation of terms but failed to consider the right hand side of the equation as part of carrying out the plan.

As to the respondents' skill in looking back, Table 1 reveals that the respondents are all 'Proficient', except respondents $\mathrm{H}$ and I, because they all substituted the answer 22 into the equation to verify their answer. Respondent $\mathrm{H}$ was rated 'Developing' for he used equation $8 x$ $+2 m=220$ where 22 was substituted to both $x$ and $m$ where in fact 22 was the value of $m$ in 
his computation. Respondent I was rated 'Beginning' in terms of looking back for he did not verify and check his answer.

Problem 2: Allan could finish his job in eight days. After working for three days he stopped and Ben finished the job in three more days. How long will it take for Ben to finish the same job alone?

Table 2.

Respondents' Level of Proficiency in Problem 2

\begin{tabular}{lllll}
\hline Respondent & $\begin{array}{l}\text { Understanding the } \\
\text { Problem }\end{array}$ & Devising a Plan & $\begin{array}{l}\text { Carrying out the } \\
\text { Plan }\end{array}$ & Looking Back \\
\hline A & D & D & P & B \\
B & D & D & P & B \\
C & D & D & P & B \\
D & D & D & P & B \\
E & D & D & P & P \\
F & B & D & P & B \\
G & D & D & D & B \\
H & D & B & P & P \\
I & B & D & D - Developing & B - Beginning
\end{tabular}

Table 2 shows the levels of proficiency of mathematics pre-service teachers in Problem 2 and reveals that respondents A, B, C, D, E, H, and J are considered 'Developing' in terms of understanding the problem for they were not able to give the adequate details of the problem. Respondents $\mathrm{A}, \mathrm{D}$, and $\mathrm{H}$ equated $x$ and $y$ into Allan and Ben without emphasizing that such variables are representing the number of days it took both of them to finish their works. Respondents B and J on the other hand represented Allan's work as 3/8 and that of Ben's is $3 / B$, while respondent $\mathrm{C}$ equated $\mathrm{A}$ into 8 and $\mathrm{B}$ into $B+3$ as the details he was able to extract from the statement.

Those coded as 'Beginning' were respondents F, G, and I. Respondent F said that $3+$ $x$ is the number of days it will take Ben to finish the job alone. Respondent $\mathrm{G}$ merely equated $x$ into $3 / 8$ and $3 / y$ without indicating what they stood for in the problem. Respondent I was not able to write anything.

In terms of devising a plan, Table 2 shows that all of the respondents were rated 'Developing' except I who is 'Beginning' which means they all had a marginal plan and did not follow it to conclusion. Respondents B and $\mathbf{J}$ merely expressed their equation as 3:8 and 3: $B$ while respondents A, C, D, E, and $\mathrm{G}$ devised their plan by formulating equation $3 / 8=3 / Y$. Respondent I was rated 'Beginning' for he expressed his equation as the sum of 8 and 3 where 3 is subtracted as well $(8+3-3)$ which is obviously an algebraic expression only and not an equation. 
It can also be seen from Table 2 that all of the respondents are rated 'Proficient' in terms of carrying out the plan except respondent I who was rated 'Developing' as he added 8 and 3 where 3 is also subtracted $(8+3-3)$ without equating it in each step. Respondent I did not use any variable in his equation to represent the unknowns. He purely used numbers in his calculation where he later obtained 9 as the number of days it will take Ben to finish the job.

Respondents A, C, D, E, and H crossed multiplied 3 of the left hand side with y on the right hand side, and 8 of the left hand side with 3 of the right hand side so they later obtained 8 as the answer. Although their answer was incorrect, they were rated 'Proficient' for they successfully obtained the correct value following mathematical operations such as multiplication and division, and using mathematical property such as multiplicative inverse according to their plan. Respondents B and J were rated 'Proficient' as well but they correctly used ratio and proportion in their calculation which is almost the same with the process used by the abovementioned respondents in their calculation. They also obtained 8 as the value of the unknowns. Respondent $\mathrm{F}$ equated the sum of 3 and the number with 8 and correctly transposed 3 on the right hand side of the equation using addition property of equality so he obtained 5 as the value of $x$, he was rated 'Proficient' for he precisely manipulated the coefficients in his equation although his answer was incorrect.

In terms of looking back, only respondent $\mathrm{F}$ who was able to verify his answer as he used his equation $3+x=8$ and directly substituted 5 into $x$ to make both sides of the equation balance. Thus, he was given a rate of 'Proficient' while the rest were rated 'Beginning' for they were not able to check their answers.

Table 3.

Respondents' Level of Proficiency in Problem 3

\begin{tabular}{lllll}
\hline Respondent & $\begin{array}{l}\text { Understanding the } \\
\text { Problem }\end{array}$ & Devising a Plan & $\begin{array}{l}\text { Carrying out the } \\
\text { Plan }\end{array}$ & Looking Back \\
\hline A & D & P & P & P \\
B & AP & P & P & P \\
C & AP & B & P & B \\
D & AP & P & D & P \\
E & B & D & P & B \\
F & B & P & D & P \\
G & D & P & B & P \\
H & D & P & P & B \\
I & B & P & D - Developing & B - Beginning
\end{tabular}

Problem 3: Given that Rigor is three times as old as Jack, and that Rigor's age was two more than five times Jack's age four years ago.

In Problem 3 the respondents were required to determine the ages of Rigor and Jack. Table 3 reveals that respondents B, C, D, and J are 'Approaching Proficiency' in terms of 
understanding the problem for they adequately defined the problem. All were able to express Rigor and Jack's ages in terms of $\mathrm{R}$ and $\mathrm{J}$ for their present ages, $R-4$ and $J-4$ for their ages four years ago.

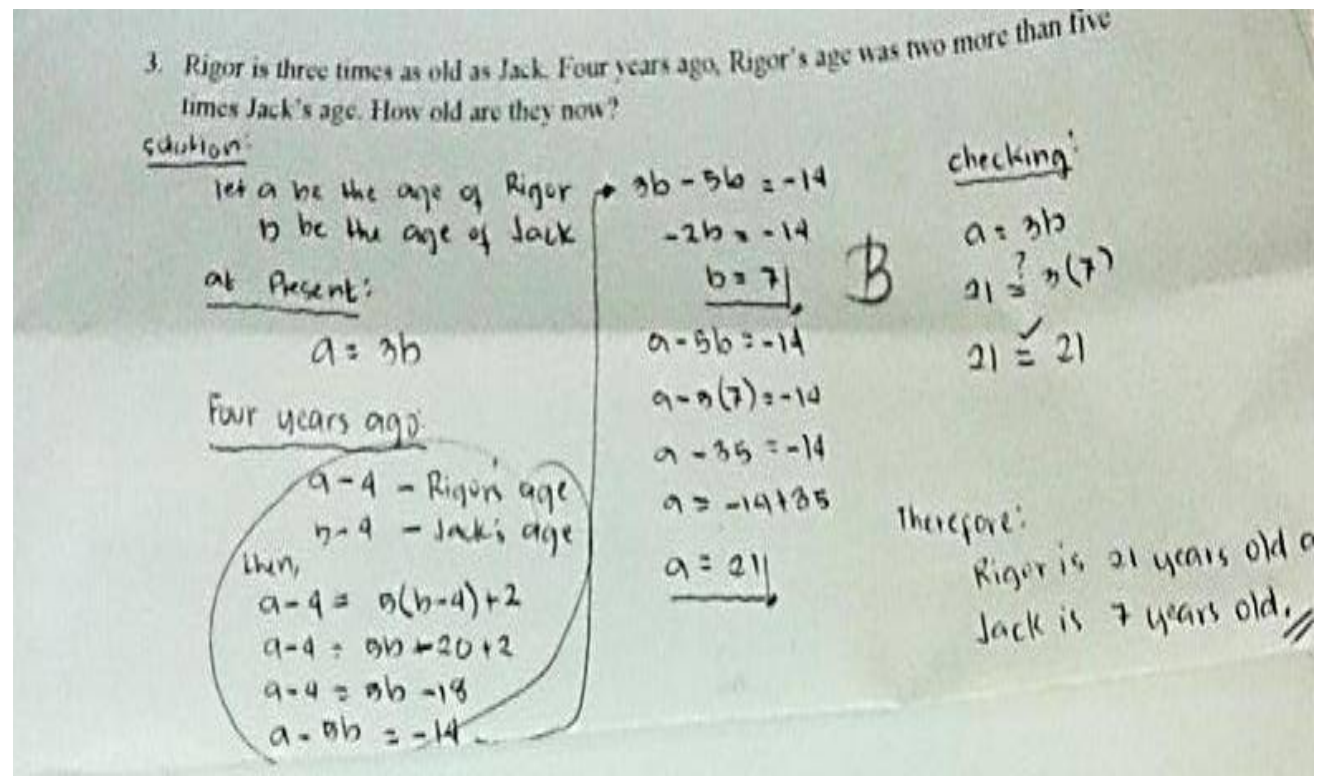

Figure 2. Sample of respondent's answers on Problem 3

It can be seen in Figure 2 that respondent B classified the ages of Rigor and Jack in present and past. However, although he was the most systematic in presenting the given values and variables he mistakenly wrote the equation $a=3 b$ to represent the said unknowns. Respondents $\mathrm{C}, \mathrm{D}$, and $\mathrm{J}$ indicated only the present and past ages of the names mentioned in the problem.

Respondents A, G, and $\mathrm{H}$ on the other hand were rated 'Developing' for they expressed the ages of Rigor and Jack at present only and did not differ in their way of understanding the problem.

Respondents E, F, and I were rated 'Beginning' in understanding Problem 3 for they were not able to identify information needed from the statement. Respondent $\mathrm{E}$ wrote $3 x$ without indicating what did it represent while respondent $\mathrm{F}$ equated $\mathrm{x}$ into $3 y$ and considered it the age of Rigor without clearly stating whether it is his age for the present or for the past. Furthermore, respondent I was rated 'Beginning' in understanding the problem for he expressed Rigor's age as $3 x(2+5)=0$ and Jack's age as $3(7)=21$ which are obviously classified as equations and not as phrases extracted correctly from the statement.

In terms of devising a plan, it can be inferred from Table 3 that respondents $\mathrm{A}, \mathrm{B}, \mathrm{D}, \mathrm{F}$, G, H, I, and J are 'Proficient' for they developed a clear and concise plan to solve the problem by formulating equation matched against the problem correctly. Respondents A, D, G, and H used $\mathrm{R}$ and $\mathrm{J}$ as their variables in their equation. They all have $R-4$ in the left hand side and $5(\mathrm{~J}$ 4) +2 on the right hand side of their equation. 
Respondent $\mathrm{C}$ on the other hand was rated 'Beginning' in devising a plan for he was not able to develop a coherent plan to solve the problem or even formulate an equation for the problem, while respondent E was given a rate of 'Developing' as they developed a marginal plan but did not follow it to conclusion. Respondent $\mathrm{E}$ had $R-4$ on the left hand side of his equation with $2+5 x$ on the other side which indicated that he was not able to formulate an equation precisely.

In terms of carrying out the plan, Table 3 reveals that respondents $\mathrm{A}, \mathrm{B}, \mathrm{D}, \mathrm{F}, \mathrm{H}$, and $\mathrm{J}$ are 'Proficient' as they used their prior knowledge accurately on mathematical operations and properties.

Table 4 reveals that the mathematics pre-service teachers except respondents B and D are all 'Beginning' in terms of understanding the problem. Problem 4 required them to determine the dimensions of the largest rectangle that can be inscribed in the ellipse $x^{2}+4 y^{2}=$ 16. Respondents B and D were rated 'Developing' as they were able to sketch a rectangle inscribed in an ellipse with centers positioned at the point of origin of the two dimensional planes. This indicates that they had an overview of the problem but important details to be extracted from the problem were not involved by them in setting up the given values and unknowns so they still failed to define the problem adequately.

As to the way respondents attempted to understand the problem, only respondent B was able to set up his given as $a^{2}=16, b^{2}=4$, and $c=\sqrt{12}$ although he did not emphasize where they were derived. Respondents F, I, and J were not able to write anything in their papers and were rated 'Beginning'. Data generated from the focus group discussion revealed that the respondents encountered difficulties in understanding the problem they had not previously encountered. They claimed that they can determine the dimensions of the ellipse and rectangle when separated for they will simply use the formulas but with regard to the way they were combined was indeed a difficult task for them to complete.

Table 4.

Respondents' Level of Proficiency in Problem 4

\begin{tabular}{lllll}
\hline Respondent & $\begin{array}{l}\text { Understanding the } \\
\text { Problem }\end{array}$ & Devising a Plan & $\begin{array}{l}\text { Carrying out the } \\
\text { Plan }\end{array}$ & Looking Back \\
\hline A & B & D & AP & B \\
B & D & D & D & B \\
C & B & D & AP & B \\
D & D & D & AP & BP \\
E & B & D & B & B \\
F & B & D & AP \\
G & B & D & AP & B \\
H & B & B & B & B \\
I & B & B & B & B \\
J & B & D - Developing & B - Beginning
\end{tabular}


In terms of devising a plan, respondents $\mathrm{A}, \mathrm{B}, \mathrm{C}, \mathrm{D}, \mathrm{E}, \mathrm{G}$, and $\mathrm{H}$ used the equation $\left(x^{2}+4 y^{2}=16\right)$ stated in the problem and multiplied both sides by $1 / 16$ using multiplicative inverse property of equality so they came up with another equation $\frac{x^{2}}{16}+\frac{y^{2}}{4}=1$. Thus, they were rated 'Developing' which means that they developed a marginal plan and did not follow it to conclusion. Only respondent A directly derived his equation from $x^{2}+4 y^{2}=16$. Respondent $\mathrm{B}$ was also given a rate 'Developing' but his equation is different from the majority as he used the formula in determining the perimeter $(P=2 L+2 W)$ of a rectangle, however, he was not able to give the other details of the problem in his equation.

Respondents F, I, and J, were unable to write anything on their papers and were rated 'Beginning'. Focus group discussion revealed that they used the equation stated in the problem and multiplied its quantities on the both sides for they remembered the steps in determining the length of the parts of the ellipse.

In terms of carrying out the plan, the majority of the respondents (A, C, D, E, G, and H) are 'Approaching Proficiency' as they used adequate information such as mathematical properties that they related to their equation for calculations and computations. In the group, respondents $\mathrm{A}, \mathrm{C}, \mathrm{D}, \mathrm{E}, \mathrm{G}$, and $\mathrm{H}$ used same steps in reaching 4 and 2 as coefficients of $a$ and $b$ but only respondent $\mathrm{H}$ showed that such coefficients were expressed as square roots of the said variables. Respondents $\mathrm{D}$ and $\mathrm{G}$ wrote the equation $y^{2}=4 a x$ after their computation. When they were asked what the equation indicated in their solution, they said that it is vague to them as they just remembered a particular equation in ellipse and inserted it to their answer for additional information.

Respondent B was rated 'Developing' as she had come up with $2 L$ as her final answer where in fact she had $2 L+4$ in her third step after 2 was substituted into $W$. This implied that she failed to adapt correctly the rule in adding dissimilar terms.

Since none of the respondents was able to attempt to verify their answer, they then were rated 'Beginning' indicating that they did not analyze their answers before reaching their conclusions.

Problem 5: Prove that every even integer that is the square of an integer is an integral multiple of four.

Table 5 reveals that respondents A, D, E, and I are 'Developing' in terms of understanding the problem for they failed to adequately define it. Respondents $\mathrm{A}$ and $\mathrm{E}$ considered $n$ the multiple integral of 4 in their given while respondent $\mathrm{D}$ used $n$ as an even integer (see Figure 3). Respondent I expressed on the other hand the $n$ as an integer and the 
square of it as the square of integer. However, they were not able to provide the unknowns and other details of the problem needed.

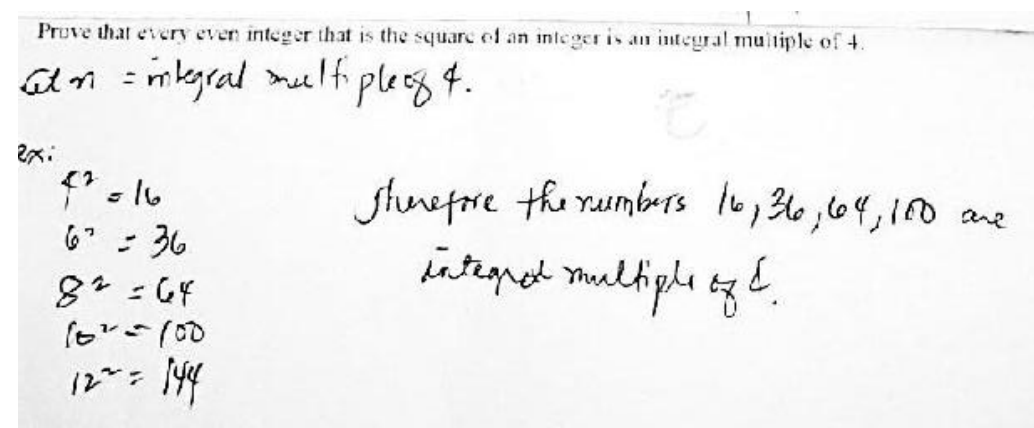

Figure 3. Sample of respondent's answers on Problem 5

Respondents B and J on the other hand were rated 'Approaching Proficiency' for they made a clear presentation of the given. They gave the complete details as they both involved variables representing set of integers. They also classified variables representing set and elements. However, they were not able to emphasize the thing that they need to prove. Furthermore, it can be seen that respondents B and $\mathrm{J}$ did not differ in the set up and the symbols they utilized.

Table 5.

Respondents' Level of Proficiency in Problem 5

\begin{tabular}{lllll}
\hline \multirow{2}{*}{ Respondent } & $\begin{array}{l}\text { Understanding the } \\
\text { Problem }\end{array}$ & Devising a Plan & $\begin{array}{l}\text { Carrying out the } \\
\text { Plan }\end{array}$ & Looking Back \\
\hline A & D & D & AP & B \\
B & AP & D & D & B \\
C & B & D & D & D \\
D & D & AP & D & B \\
E & D & D & D & B \\
F & B & D & D & B \\
G & B & D & D & D \\
H & B & D & D & B \\
I & D & D & D & B \\
J & AP & D & \multirow{2}{*}{ D - Developing } & B - Beginning
\end{tabular}

Respondents B, C, F, and $\mathrm{H}$ are considered 'Beginning' in terms of understanding the problem for they failed to identify the problem. Respondents $\mathrm{C}$ and $\mathrm{H}$ did not set up their given while respondent $\mathrm{C}$, although making an initial step in setting up the given, expressed the square of $n$ only without giving emphasis on what it represented.

As to mathematics pre-service teachers' performances in devising a plan for Problem 5, it can be seen in Figure 2 that all of the respondents, except respondent D, are 'Developing' which means that they provided a marginal plan on the problem but they did not follow it to conclusion. Respondents C, E, G, and I merely expressed the squares of even integers such as $2,4,6,8$, and 10 without having a general equation that could stand for the said numbers which 
was required in proving. Respondent $\mathrm{A}$ was able to form her equation but variables in it are not emphasized whether they represent an even integer or an integral multiple of 4 . Respondent $\mathrm{D}$

formulated $n=\frac{n^{2}}{4}$ as his general equation of the problem and expressed it in fraction form. He is rated 'Approaching Proficiency' for he developed an equation that could stand for the set of even integers expressed in their squares, and followed it to conclusion, although it does not totally represent the idea of the statement.

Table 5 also shows that majority of the respondents (except respondent A) is 'Developing' in terms of carrying out the plan for they directly expressed the squares of the integers without having a general equation where they have been anchored to. Respondents $\mathrm{C}$, D, E, F, G, H, and I had come up with 4, 16, 36, and 64 after getting the squares of 2, 4, 6 and 8 without having a basis on how they obtained them and did not establish an equation needed for proving. Respondents B and J on the other hand were rated 'Developing' for they expressed the square of 2 into 4 and no further integers were used in the proof.

Among the mathematics pre-service teachers only respondent $\mathrm{A}$ was rated 'Approaching Proficiency' in terms of carrying out the plan for she had her general equation followed by her calculations on even integers such as 2, 4, 6, 8, and 10 expressed in their squares. This implied that she utilized her equation for proving by using the mentioned even integers.

As to looking back as the skills to be utilized in problem solving, only respondents $\mathrm{C}$, $\mathrm{G}$, and $\mathrm{H}$ were able to verify their answers as they examined the values they have obtained in their calculations in a way that were divided by 4 . However, they were rated 'Developing' for they were not able to prove in their checking that every even integer that is a square of an integer is an integral multiple of 4 .

\section{Conclusion}

The mathematics pre-service teachers had difficulties in understanding the problem stages as they failed to define the problems adequately. They also had a problem in devising a plan because they could not accurately formulate equations based on the information given in the problems. Moreover, they provided an inadequate interpretation of the findings and did not derive a logical solution to the problems. However, they are 'Approaching Proficiency' in terms of carrying out the plan as they had a good foundation in performing basic analysis and mathematical operations.

\section{Recommendation}

While the results of this study cannot be generalized due to the small sample and there is no claim that the sample represents all Filipino pre-service teachers, for this group the 
findings of this study may be used by the mathematics faculty in considering the inclusion of more problem solving in the learning experiences of these mathematics pre-service teachers for they find it interesting and exciting. This could also be a preparation for them in their entrance to teaching profession. Mathematics lecturers could encourage a constructivist approach in teaching mathematics to develop sufficient problem solving skills of pre-service teachers.

Furthermore, school administrators could encourage and monitor the faculty over the incorporation of problem solving in mathematics classes for developing mathematics preservice teachers' acquisition of well-honed skills in problem solving. The school heads could also inform the faculty of the poor performances of the prospective mathematics educators in problem solving to enlighten them on the necessary steps to take to deliver instruction effectively to the students.

Finally, the mathematics pre-service teachers of Cotabato City could be informed of their poor performances in problem solving to realize how they are going in order to cultivate their skills in problem solving and to readily face their future students and career.

\section{References}

Ader, E. (2014). A framework for understanding teachers' promotion of students' metacognition. Istanbul, Turkey: Bogazici University.

Culaste, C. (2011). Cognitive skills of mathematical problem solving of grade 6 children. Retrieved from http://www.auamii.com/jiir/Vol-01/issue-01/X12.Culaste.pdf

English, L., Lesh, R., \& Fennewald, T. (2008). Future directions and perspectives for problem solving research and curriculum development. Paper presented at the $11^{\text {th }}$ International Congress in Mathematics Education, July 6-13, 2008, Mexico.

Jakel, F., \& Schreiber, C. (2013). Introspection in problem solving. Retrieved from http://www.docs.hss.ed.ac.uk/iad/Learning_teaching/Academic_teaching/Resources/E xperience_of_learning/EolChapter8.pdf

Kerry, T., \& Wilding, M. (2004). Effective classroom teacher: Developing the skills you need in the classroom. London: Pearson Education.

Laurillard, D. (n.d.). Styles and approaches in problem solving. Retrieved from http://www.docs.hss.ed.ac.uk/iad/Learning_teaching/Academic_teaching/Resources/E xperience_of_learning/EolChapter8.pdf

Merriam, S. B. (2009). Qualitative research: A guide to design and implementation: Revised and expanded from qualitative research and case study applications in education. San Franscisco: Jossey-Bass.

Ogena, E., Lana, R., \& Sasota, R. (2010). Performance of Philippine high schools with special curriculum in the 2008 Trends in International Mathematics and Science Study (TIMSS-Advanced). Retrieved from 
http://nap.psa.gov.ph/ncs/11thNCS/papers/invited\%20papers/ips-

07/01_Performance\%20of\%20Philippine\%20High\%20Schools\%20With\%20Special $\% 20$ Science $\% 20$ Curriculum $\% 20$ In $\% 20$ The $\% 202008 \% 20$ Trends $\% 20$ in $\% 20$ Internatio nal\%20Mathematics\%20and\%20Science\%20Study\%20(TIMMS-Advanced).pdf

Polya, G. (1954). How to solve it. Princeton: Princeton University Press.

Sangcap, P. (2010). Mathematics-related beliefs of Filipino college students: Factors affecting mathematics and problem solving performance. Retrieved from http://ac.elscdn.com/S1877042810021695/1-s2.0-S1877042810021695-main.pdf?_tid=d359fe4425bb-11e4-a77e 00000aab0f6c\&acdnat=1408245116_b69abd9e8646ef7a692c4a5c66 fbbc76

Yuan, S. (2013). Incorporating Polya's problem-solving method in remedial class. Journal of Humanistic Mathematics, 3. 

Southeast Asian Mathematics Education Journal 2017, Vol. 7 No. 2 